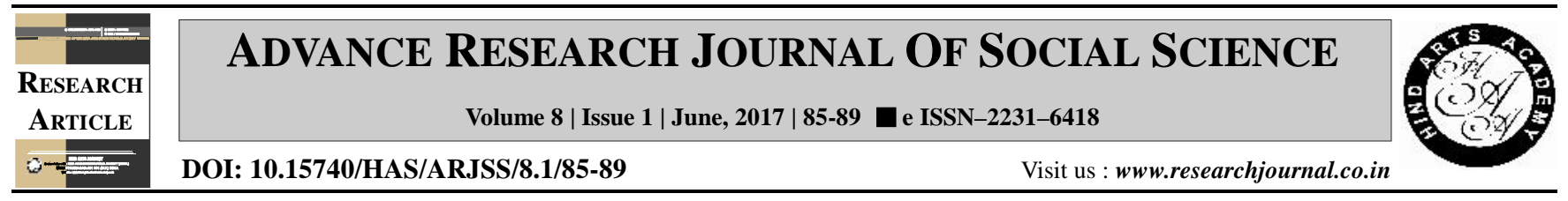

\title{
Effect of physical load on workers involved in grape cultivation
}

Savita Kumari* and Manju Mehta

Department of Family Resource Management, C.C.S. Haryana Agricultural University, HISAR (HARYANA) INDIA

(Email: jrozydhiman@gmail.com)

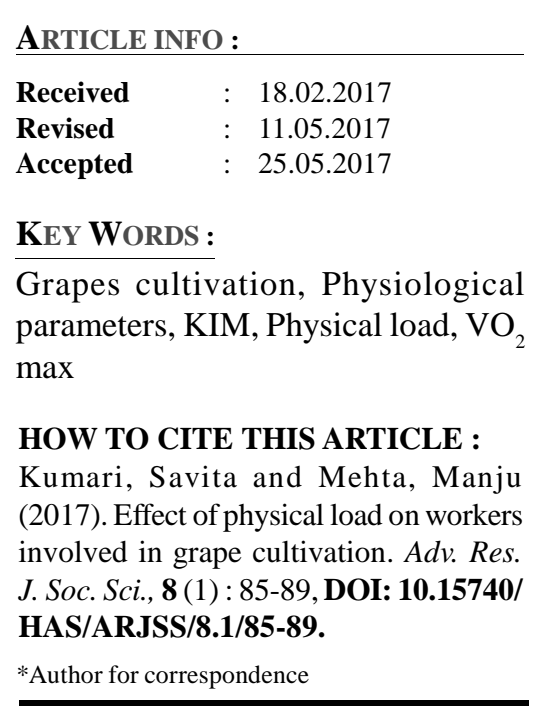

\begin{abstract}
The aim of this study was to find out the effect of physical load on workers involved in grape cultivation. The research designs comprised on field study conducted on 15 respondents were engaged on grapes cultivation activities. Physical fitness was determined by calculating the physiological parameters i.e. blood pressure, body temperature, pulse rate and $\left(\mathrm{VO}_{2}\right.$ max). Occupational risk was assessed through physical load parameters viz., Physical load. The results indicated that mean height and weight of workers involved grape activities was $159.9 \mathrm{~cm}$ and $64.2 \mathrm{~kg}$, respectively. BMI was observed as $21.8 \mathrm{~kg} / \mathrm{m}^{2}$, fat percentage was worked out to 29.9 per cent, and hence LBM was $44.1 \mathrm{~kg}$ with variation of $\pm 19.3 \mathrm{~kg}$. $\mathrm{VO}_{2}$ max was found to be $31.8 \mathrm{ml} / \mathrm{kg} \mathrm{x}$ min exhibiting that the subjects were having good health. Conclusively there was no effect of grapes cultivation activities on body temp., pulse pressure of the workers. On the basis of physical load in the grape cultivation occupational risk was highest in pruning (178) followed by harvesting activity (153.05) and least was in plant protection activity (61.5).
\end{abstract}

